\title{
Diabetes Mellitus in a J apanese Girl with HDR Syndrome and GATA3 Mutation
}

\author{
KOJI MUROYA ${ }^{1), 2)}$, TAKAHIRO MOCHIZUKI ${ }^{3)}$, MAKI FUKAMI ${ }^{1)}$, MANAMI ISO ${ }^{1)}$, KEINOSUKE FUJITA ${ }^{3)}$, \\ MITSUO ITAKURA ${ }^{4)}$ AND TSUTOMU OGATA ${ }^{1)}$ \\ ${ }^{1)}$ Department of Endocrinology and Metabolism, National Research Institute for Child Health and Development, Tokyo, Japan \\ ${ }^{2)}$ Department of Endocrinology and Metabolism, Kanagawa Children's Medical Center, Yokohama, Japan \\ ${ }^{3)}$ Department of Pediatrics, Children's Medical Center, Osaka City General Hospital, Osaka, Japan \\ ${ }^{4)}$ Institute for Genome Research, Tokushima University, Tokushima, Japan
}

\begin{abstract}
We report on a Japanese girl with HDR (hypoparathyroidism, sensorineural deafness, and renal dysplasia) syndrome who developed diabetes mellitus (DM) at three years of age (blood glucose $713 \mathrm{mg} / \mathrm{dL}, \mathrm{HbA}_{1 \mathrm{c}} 8.0 \%$ ) in the absence of anti-glutamic acid decarboxylase autoantibodies. Mutation analysis revealed a de novo heterozygous two base pair deletion at exon 6 of the GATA3 gene (c.1200_1201delCA; p.H400fsX506). GATA3 expression was identified by PCR amplification for human pancreas cDNA, and mouse Gata3 was weekly but unequivocally expressed in pancreatic $\beta$ cells. The results, in conjunction with the previous findings indicating the critical role of GATA3 in lymphocyte function, suggest that GATA3 haploinsufficiency may affect the function of $\beta$ cells and/or lymphocytes, leading to the development of DM in relatively exceptional patients with high susceptibility to DM.
\end{abstract}

Key words: Diabetes mellitus, Expression, GATA3, HDR syndrome

HDR (hypoparathyroidism, sensorineural deafness, and renal dysplasia) syndrome is an autosomal dominant disorder first reported by Bilous et al. [1]. This condition is primarily caused by haploinsufficiency of GATA3 on chromosome 10p15, although a GATA3 mutation has not been identified in several patients with HDR syndrome-compatible clinical features [2, 3]. GATA3 consists of six exons, and encodes a transcription factor with two transactivation domains and two zinc finger domains [2]. GATA3 is expressed in the developing parathyroid glands, inner ears, and kidneys, together with thymus and central nervous system $[4,5]$. While several non-triad features such as pyloric stenosis, ventricular septal defect, polycystic ovary, abnormal Müllerian duct structures, and hemimegalencephaly have been described in several patients with GATA3 mutations [3, 6-8], there is no report docu-

Received Oct. 26, 2009; Accepted Nov. 19, 2009 as K09E-313 Released online in J-STAGE as advance publication Dec. 1, 2009

Correspondence to: Dr. Tsutomu OGATA, Department of Endocrinology and Metabolism, National Research Institute for Child Health and Development, 2-10-1 Ohkura, Setagaya, Tokyo 157-8535, Japan. E-mail: tomogata@nch.go.jp menting diabetes mellitus (DM) in this condition.

Here, we report a patient with DM and a GATA3 mutation, and discuss a potential relationship between DM and a GATA3 mutation.

\section{Case Report}

This Japanese girl was born at 37 weeks of gestation after an uncomplicated pregnancy and delivery. At birth, her length was $43.0 \mathrm{~cm}(-2.4 \mathrm{SD})$ and her weight $1.74 \mathrm{~kg}$ (-3.1 SD). The non-consanguineous parents and the younger brother were clinically normal.

At 3 months of age, she was admitted to Osaka City Medical Center because of frequent vomiting and irritability. Routine laboratory tests revealed hypocalcemia $(7.8 \mathrm{mg} / \mathrm{dL}$ ) (age- and sex-matched Japanese reference value, 9.8-11.6 mg/dL) and hyperphosphatemia $(8.3 \mathrm{mg} / \mathrm{dL})(5.1-7.1 \mathrm{mg} / \mathrm{dL})$, and subsequent biochemical studies showed parathyroid hormone (PTH) deficiency (intact PTH, below $5 \mathrm{pg} / \mathrm{mL}$ ) $(10-50 \mathrm{pg} / \mathrm{mL})$. Thus, $1 \alpha-(\mathrm{OH})$ vitamin $\mathrm{D}$ therapy was started, successfully normalizing serum calcium and phosphate values. At 12 months of age, since she 
responded poorly to sounds, auditory brainstem response was performed, indicating severe sensorineural deafness with hearing levels being $80 \mathrm{~dB}$ for the right ear and $100 \mathrm{~dB}$ for the left ear (normal range, below 25 $\mathrm{dB})$. Thus, hearing aids were utilized in her daily life.

At 3 years of age, she showed polydipsia, polyuria, and weight loss, and was diagnosed as having DM because of elevated blood glucose (713 mg/dL) (70-110 $\mathrm{mg} / \mathrm{dL})$ and $\mathrm{HbA}_{1 \mathrm{c}}$ (8.0\%) (4.3-5.8\%). Serum insulin was $8.0 \mu \mathrm{U} / \mathrm{mL}(1.7-10.4 \mu \mathrm{U} / \mathrm{mL})$ and C-peptide 1.1 $\mathrm{ng} / \mathrm{mL}(0.6-1.8 \mathrm{ng} / \mathrm{mL})$. She was immediately placed on insulin therapy ( $\sim 0.7 \mathrm{U} / \mathrm{kg} /$ day). Urine C-peptide gradually decreased and became undetectable at eight years of age; at that time, she required insulin therapy of $1.08 \mathrm{U} / \mathrm{kg} /$ day. Anti-glutamic acid decarboxylase autoantibodies (anti-GAD Abs) were negative throughout the clinical course. At nine years of age, she was found to have elevated blood urea nitrogen (61.3 mg/dL) (7.5-19.3 mg/dL) and creatinine (2.0 $\mathrm{mg} / \mathrm{dL})(0.4-0.8 \mathrm{mg} / \mathrm{dL})$ at the time of periodical follow-up examinations for DM. Thus, renal echography and scntigraphy were performed, showing right renal aplasia and left renal hypoplasia. Other abdominal visceral organs including the pancreas exhibited apparently normal structures on the ultrasound examinations. Chromosome analysis revealed a 46,XX karyotype in all the 50 lymphocytes examined. On the basis of the above findings, she was diagnosed as having HDR syndrome and DM. At present, she is 12 years old, and shows short stature ( $-4.5 \mathrm{SD}$ ) and some pubertal development (breast, Tanner stage 2). Current insulin dosage is $1.17 \mathrm{U} / \mathrm{kg} /$ day, and her DM has been well controlled with HbA1c value being maintained around $6.0 \%$.

\section{Methods}

\section{Mutation analysis of GATA3}

This study was approved by the Institutional Review Board Committee at National Center for Child Health and Development. After obtaining informed consent, leukocyte genomic DNA samples of the patient and the parents were PCR-amplified for the coding exons $2-6$ and their splice sites, and the PCR products were subjected to direct sequencing from both directions on a CEQ 8000 autosequencer (Beckman Coulter, Fullerton, CA). The primer sequences and the PCR conditions were as described previously $[2,3]$. To confirm a heterozygous mutation, the correspond- ing PCR products were subcloned with a TOPO TA Cloning Kit (Invitrogen, Carlsbad, CA), and normal and mutant alleles were sequenced separately.

\section{PCR amplification of human pancreas cDNA}

Human pancreas cDNA was purchased from Clontech (Mountain View, CA), as well as fetal kidney cDNA utilized as a positive control. PCR amplification was performed with $0.5 \mathrm{ng}$ of cDNA samples, using the forward primer for exon 5 (5'-GAATGCCAATGGGGACCCTGT-3') and the reverse primer for exon 6 (5'-TTCATGCCTTACAGCTACCCAGA-3').

\section{In situ hybridization (ISH) analysis for the mouse pancreas}

Fifteen-week-old female BDF1 mice (Clea Japan, Tokyo) were anesthetized with sodium pentobarbital and fixed by cardiac perfusion with Mildform10N (Wako Pure Chemical Industries, Osaka). Pancreatic tissues were dissected and fixed with the same fixative for 48 hours at room temperature. The tissues were embedded in paraffin, and serial tissue sections were prepared at $5 \mu \mathrm{m}$ thickness. ISH analysis was performed with BlueMap Kit and Discovery automatic staining modules (Ventana Medical Systems, Tucson, AZ) according to manufacturer's instructions. cDNAs of mouse Ins-1 (an insulin-like peptide orthologous to human insulin) (nt 653-1117, GenBank accession no. X04725) and Gata3 (nt 1566-2002, GenBank accession no. NM_008091) were amplified by reverse transcription PCR and subcloned into pCR4Blunt-TOPO (Invitrogen). Sense and antisense digoxigenin-labeled RNA probes were synthesized using T7 or T3 RNA polymerase in the presence of digoxigenin-labeled dUTP following the manufacturer's protocol (Roche Molecular Biochemicals, Indianapolis, IN).

\section{Results}

\section{Mutation analysis of GATA3}

This patient had a heterozygous two base pair deletion at exon 6 (c.1200_1201delCA) of GATA3 that is predicted to cause a frameshift at the 400th codon for the histidine and resultant termination at the 506th codon (p.H400fsX506) (Fig. 1). This mutation was absent from the parents.

\section{PCR amplification of human pancreas cDNA}

PCR products of $690 \mathrm{bp}$ long were identified in fe- 
tal kidney after 25 cycles and in pancreas after 40 cycles (Fig. 2A). This indicated relatively weak GATA3 expression in the pancreas.

\section{ISH analysis for the mouse pancreas}

Anti-sense probes for Gata3 detected weak but definitive signals in cells with strong Ins-1 expression (Fig. 2B). This showed specific Gata3 expression in the mouse pancreatic $\beta$ cells.

\section{Discussion}

This patient had the triad of the HDR syndrome and a heterozygous mutation of GATA3. This is consistent with the previous data indicating that GATA3 mutations are usually identified in patients with two or three of the HDR triad features $[9,10]$.

The salient feature of this patient is the development of DM. This may be co-incidental, because DM has not been identified in patients with GATA3 mutations. However, human GATA3 was identified in the human pancreas cDNA sample, and mouse Gata3 was weekly but unequivocally expressed in pancreatic $\beta$ cells. In addition, GATA3 is known to play an important role in lymphocyte development and function [11, 12]. Thus, GATA3 haploinsufficiency may affect the function of $\beta$ cells and/or lymphocytes, leading to the development of DM in relatively exceptional patients with high sus-

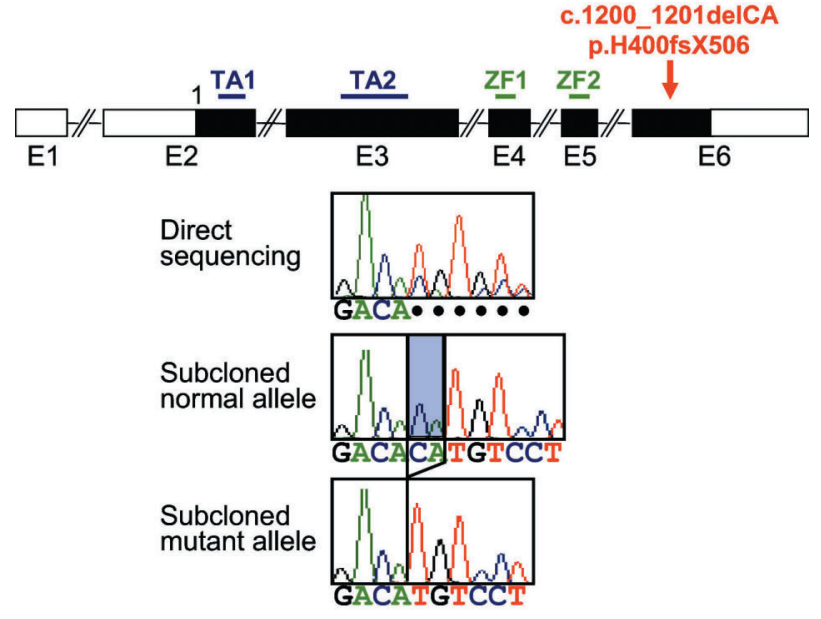

Fig. 1. Mutation analysis of GATA3.

Upper diagram: The genomic structure of GATA3. The black and white boxes denote the coding and the untranslated regions, respectively. TA1 and TA2 denote two transactivation domains, and ZF1 and ZF2 represent two zinc finger domains.

Lower diagram: The electrochromatograms delineate the c.1200_1201delCA (p.H400fsX506) mutation at exon 6. This mutation has been indicated by the direct sequencing, and confirmed by the subsequently performed sequencing of the subcloned normal and mutant alleles.

ceptibility to DM because of other genetic and environmental factors. In this regard, the absence of antiGAD Abs may argue for possible $\beta$ cell, rather than lymphocyte, dysfunction [13].

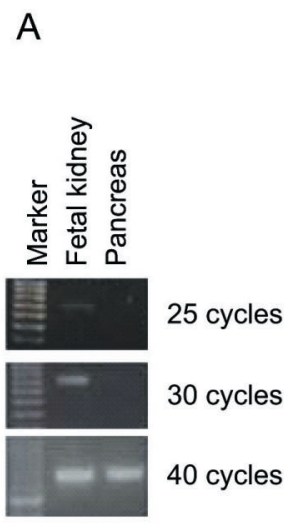

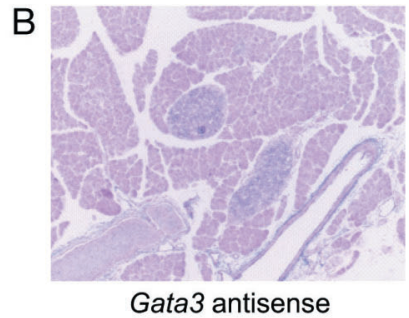

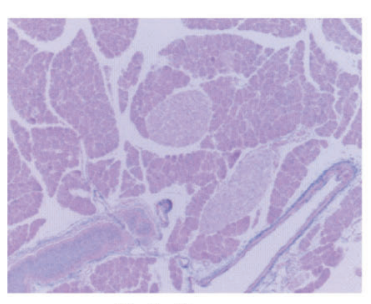

Gata3 sense
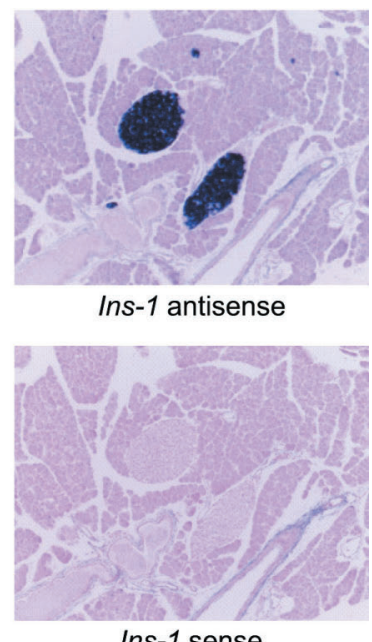

Ins-1 sense

Fig. 2. Expression analyses of GATA3/Gata3.

A. PCR-amplification using human cDNA samples. GATA3 expression is identified after 25 cycles in the fetal kidney, and after 40 cycles in the pancreas.

B. ISH analysis using the mouse pancreas. The antisense probe for Gata3 detects weak but positive signals in the cells with strong expression of Ins-1 ( $\beta$ cells). No signals have been identified by the sense probes. 
The frameshift mutation resided on the last coding exon 6. Since the position of the mutation satisfies the condition for the escape from nonsense mediated mRNA decay [14], it is possible that an aberrant GATA3 protein is produced, leading to the development of DM due to a dominant negative effect. However, this possibility is unlikely, because previously reported patients with nonsense or frameshift mutations on exon 6 are free from DM $[3,10]$.

In summary, we observed a patient with a GATA3 mutation and DM. Further studies will clarify whether GATA3 mutations can be a risk factor for the development of DM.

\section{Acknowledgements}

This work was supported in part by grants for Child Health and Development and for Research on Children and Families from the Ministry of Health, Labor, and Welfare.

\section{References}

1. Bilous RW, Murty G, Parkinson DB, Thakker RV, Coulthard MG, Burn J, Mathias D, Kendall-Taylor P (1992) Autosomal dominant familial hypoparathyroidism, sensorineural deafness, and renal dysplasia. $N$ Engl J Med 327: 1069-1074.

2. Van Esch H, Groenen P, Nesbit MA, Schuffenhauer S, Lichtner P, Vanderlinden G, Harding B, Beetz R, Bilous RW, Holdaway I, Shaw NJ, Fryns JP, Van de Ven W, Thakker RV, Devriendt K (2000) GATA3 haplo-insufficiency causes human HDR syndrome. Nature 406: 419-422.

3. Muroya K, Hasegawa T, Ito $Y$, Nagai T, Isotani H, Iwata Y, Yamamoto K, Fujimoto S, Seishu S, Fukushima Y, Hasegawa Y, Ogata T (2001) GATA3 abnormalities and the phenotypic spectrum of HDR syndrome. J Med Genet 38: 374-380.

4. Labastie MC, Catala M, Gregoire JM, Peault B (1995) The GATA3 gene is expressed during human kidney embryogenesis. Kidney Int 47: 1597-1603.

5. Debacker C, Catala M, Labastie MC (1999) Embryonic expression of the human GATA3 gene. Mech Dev 85: 183-187.

6. Zahirieh A, Nesbit MA, Ali A, Wang K, He N, Stangou M, Bamichas G, Sombolos K, Thakker RV, Pei Y (2005) Functional analysis of a novel GATA3 mutation in a family with the hypoparathyroidism, deafness, and renal dysplasia syndrome. J Clin Endocrinol Metab 90: 2445-2450.

7. Hernández AM, Villamar M, Roselló L, MorenoPelayo MA, Moreno F, Del Castillo I (2007) Novel mutation in the gene encoding the GATA3 transcription factor in a Spanish familial case of hypoparathyroidism, deafness, and renal dysplasia (HDR) syndrome with female genital tract malformations. Am J Med Genet A 143: 757-762.

8. Adachi M, Tachibana K, Asakura Y, Tsuchiya T (2006) A novel mutation in the GATA3 gene in a family with HDR syndrome (hypoparathyroidism, sensorineu- ral deafness and renal anomaly syndrome). $J$ Pediatr Endocrinol Metab 19: 87-92.

9. Nesbit MA, Bowl MR, Harding B, Ali A, Ayala A, Crowe C, Dobbie A, Hampson G, Holdaway I, Levine MA, McWilliams R, Rigden S, Sampson J, Williams AJ, Thakker RV (2004) Characterization of GATA3 mutations in the hypoparathyroidism, deafness, and renal dysplasia (HDR) syndrome. J Biol Chem 279: 22624-22634.

10. Ali A, Christie PT, Grigorieva IV, Harding B, Van Esch $\mathrm{H}$, Ahmed SF, Bitner-Glindzicz M, Blind E, Bloch C, Christin P, Clayton P, Gecz J, Gilbert-Dussardier B, Guillen-Navarro E, Hackett A, Halac I, Hendy GN, Lalloo F, Mache CJ, Mughal Z, Ong AC, Rinat C, Shaw N, Smithson SF, Tolmie J, Weill J, Nesbit MA, Thakker RV (2007) Functional characterization of GATA3 mutations causing the hypoparathyroidismdeafness-renal (HDR) dysplasia syndrome: insight into mechanisms of DNA binding by the GATA3 transcription factor. Hum Mol Genet 16: 265-275.

11. Labastie MC, Bories D, Chabret C, Grégoire JM, Chrétien S, Roméo PH (1994) Structure and expression of the human GATA3 gene. Genomics 21: 1-6.

12. Hendriks RW, Nawijn MC, Engel JD, van Doorninck H, Grosveld F, Karis A (1999) Expression of the transcription factor GATA-3 is required for the development of the earliest $\mathrm{T}$ cell progenitors and correlates with stages of cellular proliferation in the thymus. Eur J Immunol 29: 1912-1918.

13. Eisenabrth GS, Polonsky KS, Buse JB (2008) Type 1 diabetes mellitus. In: Kronenberg HM, Melmed S, Polonsky KS, Larsen PR (eds). Williams textbook of endocrinology, $11^{\text {th }}$ ed. W.B. Saunders, Philadelphia, pp 1391-1416.

14. Kuzmiak HA, Maquat LE (2006) Applying nonsensemediated mRNA decay research to the clinic: progress and challenges. Trends Mol Med 12: 306-316. 